\title{
Connecting and empowering the Latin American research community in the global sphere: an introduction to the special issue on the metric study of regional science and technology
}

\author{
Jane M. Russell ${ }^{1} \cdot$ María Victoria Guzmán $^{2}$
}

Received: 29 March 2018/Published online: 16 April 2018

(C) Akadémiai Kiadó, Budapest, Hungary 2018

In the early 2000s, a group of Latin American specialists headed by Gilberto Sotolongo Aguilar of Cuba and Cesar Macías Chapula from México, began to forge the idea of organizing a meeting to serve as a forum for discussion and exchange of knowledge on issues associated with the metric studies of information. It was intended that this event follow the organizational model of the International Society for Scientometrics and Informetrics (ISSI) Conferences but directed principally at researchers in Ibero-America, particularly those working in Latin America. As a result, the First International Seminar on the Quantitative and Qualitative Study of Science and Technology was held in Havana, Cuba in the spring of 2002. Due to the untimely death of one of its founders, Gilberto Sotolongo, the biennial meeting from 2004 onwards, was named in his honour, "Prof. Gilberto Sotolongo Aguilar".

The Seminar has been held continuously in Havana every 2 years since then, under the auspices of the Cuban International Information Conference. The latest edition of the Seminar in 2016, coincided with the maturing of research groups from the region that work in the field of metric studies. This special issue of Scientometrics includes a selection of thirteen studies presented in this eighth edition of the event. The articles included in this special issue and the topics they address, are a representation of the growth and consolidation of the academic community of the region. An example of the above is that in 2002, only 12 papers were received and in the 2016 edition, more than 48 contributions were

Jane M. Russell

jrussell@unam.mx

María Victoria Guzmán

mvguzman@finlay.edu.cu

1 Instituto de Energías Renovables, Universidad Nacional Autónoma de México, 62580 Temixco, Morelos, Mexico

2 Finlay Institute of Vaccines, Ave. 27, No. 19805, AP. 16017 Havana, Cuba 
submitted to arbitration. Likewise, collaborative studies grew from three in 2002, to 14 in 2016, as well as the participation of new research groups and postgraduate students.

The groups that have expanded their collaboration network are those formed by the Finlay Institute of Vaccines of Cuba (IFV) with colleagues from the Autonomous University of Mexico City (UACM), The Centre for Research and Innovation in Information and Communication Technologies INFOTEC (Mexico) and the National Autonomous University of Mexico (UNAM). Also represented are the following bi- and multilateral co-authorships: National Medical Sciences Information Centre-Infomed (Cuba), the Institute of Public Goods and Policies of the Spanish National Research Council (CSIC-IPP) and the University of Granada; the Postgraduate Programme in Library and Information Studies at UNAM (Mexico) and the Centre for Research and Advanced Studies at the National Polytechnic Institute (Cinvestav-IPN); the Michoacan University San Nicolás de Hidalgo (Mexico) and the University of Antioquia (Colombia) and, finally, CSIC-IPP (Spain), the National University of La Plata (Argentina), Carlos III University (Spain) and Indiana University (USA). Other contributing institutions are the University of Alicante (Spain) and the Information and Knowledge Management Group of the University of Pinar del Río (Cuba);

Keynote papers were delivered by Dr. Wolfgang Glänzel from KU Leuven (Belgium) and the Hungarian Academy of Sciences, Budapest, in co-authorship with Lin Zhang, North China University of Water Conservancy and Electric Power, Zhengzhou (China) and by Drs. Jaime Aboites and Claudia Díaz, Economic Production Department, Metropolitan Autonomous University (Mexico).

The editors wish to give a special mention to the keynote speakers of the Eighth Seminar, Wolfgang Glänzel and Jaime Aboites, who in past editions of these meetings have shared their experience and methodological approaches of great benefit to the audience, particularly to the younger participants and new groups of researchers from the Ibero-American region. Special recognition is given to Professor Wolfgang Glänzel who has managed to overcome linguistic barriers to reach an audience that is mostly Spanishspeaking.

We also wish to thank the colleagues who have participated in the organization of this seminar over the years: Isidro Aguilló (CSIC-IPP, Spain), Francisco Collazo (Cinvestav$I P N$, Mexico), Rogério Mugnaini (University of São Paulo, Brazil), Gabriel Vélez Cuartas (University of Antioquia-Medellín, Colombia), Ricardo Arencibia (Information Technology Company, Cuba), Humberto Carrillo-Calvet (UNAM, Mexico) and María Elena Luna (Cinvestav-IPN, Mexico). Likewise, our special thanks to all the reviewers from IberoAmerica and from many other parts of the world who anonymously and disinterestedly helped to improve the scientific quality of this special issue of the journal.

A selection of papers presented at two previous editions of the Seminar in 2004 and 2014, were published in the Spanish journal, Revista Española de Documentación Científica and in the Brazilian journal, Transinformação, respectively. However, this is the first appearance of contributions from the Seminar in an international journal published entirely in English.

The present organizing committee invite the community of students and researchers in the field of metrics studies of information (Bibliometrics, Scientometrics, Informetrics, Patentometrics, Webmetrics, etc.) to join us in future editions of the Seminar: 2018 in Havana (Cuba), 2019 in Mexico City (Mexico), 2020 again in Havana (Cuba) and 2021, in Medellín (Colombia). It is hoped that the organization of the event every second year in other countries of Ibero-America will promote research activities in the field especially 
with respect to postgraduate studies and will lead to further integration of the regional specialist community.

We are pleased to have this opportunity to share with an international audience the work of the groups of researchers who participated in the VIII International Seminar on the Quantitative and Qualitative Studies of Science and Technology "Prof. Gilberto Sotolongo Aguilar" and we hope to welcome many of you to future events.

Sincerely, the editors.

Dr. Jane M. Russell

Dr. Maria Victoria Guzmán 